\title{
A 457-year reconstruction of precipitation in the southeastern Qinghai-Tibet Plateau, China using tree-ring records
}

\author{
GOU XiaoHua ${ }^{1 *}$, YANG Tao $^{1}$, GAO LinLin $^{1}$, DENG ang $^{1}$, YANG MeiXue ${ }^{2} \& \mathrm{CHEN} \mathrm{FaHu}^{1}$ \\ ${ }^{1}$ Key Laboratory of Western China's Environmental Systems (Ministry of Education) and Research School of Arid Environment and Climate \\ Change, Lanzhou University, Lanzhou 730000, China; \\ ${ }^{2}$ State Key Laboratory of Cryospheric Sciences, Cold and Arid Regions Environmental and Engineering Research Institute, Chinese Academy of \\ Sciences, Lanzhou 730000, China
}

Received June 28, 2012; accepted September 25, 2012; published online January 11, 2013

\begin{abstract}
This paper presents a 457-year reconstruction of precipitation in the southeastern Qinghai-Tibet Plateau using tree-ring records. Tree-ring samples were collected from the Hengduan Mountains in the southeastern part of the Qinghai-Tibet Plateau, China. A nearly 500-year chronology was developed using tree-ring width records. Correlation analysis shows moisture is the main factor limiting tree growth in this region. Ring-widths were significantly positively correlated with the Palmer Drought Severity Index (PDSI) and precipitation in many months. The highest correlation coefficient was found between the annual growth of trees and precipitation from the previous September to the current June (0.738). Based on this relationship, we reconstructed the precipitation history from 1509 to 2006 . The reconstruction explains $54.4 \%\left(R_{\mathrm{adj}}^{2}=53.5 \%, N=49, F=56.12\right)$ of the actual precipitation variation during the calibration period (1958-2006). During the reliable period of the reconstruction (1549-2006), some low-frequency climate signals are included, indicating this region has been getting wetter in the last 20 years. The reconstruction documents six apparently dry and five pluvial periods and the 17th century dry period lasted longer than any other. When compared with other recent studies, this study and these earlier reconstructions show a similar trend in the variation of drought and pluvial. Further spatial correlation analysis confirms that the reconstructed precipitation adequately represents the rainfall history of the entire Hengduan Mountain area. The Multi-taper method, a type of spectral analysis, reveals that precipitation in this area had significant $(P<0.01)$ spectral peaks at 3-5 a, 60 a and $79-85$ a.
\end{abstract}

Abies Mill., Hengduan Mountains, precipitation reconstruction, Qinghai-Tibet Plateau, tree-ring width

Citation: Gou X H, Yang T, Gao L L, et al. A 457-year reconstruction of precipitation in the southeastern Qinghai-Tibet Plateau, China using tree-ring records. Chin Sci Bull, 2013, 58: 1107-1114, doi: 10.1007/s11434-012-5539-7

The Hengduan Mountains, located in the southeastern rim of the Qinghai-Tibet Plateau, comprise an important cross drainage area of many rivers, such as the Jinsha, Lancang, Nujiang, Yalong rivers, and form a transition zone between the top and second step of China's three-tiered terrain with high elevations in the western step and low in eastern China. Complex terrain, various regional climates and rich biodiversity give this area high ecological significance. Hydrology, ecology and climate change may all affect regional social stability and development. For example, in 2010, five provinces in southwestern China experienced severe drought,

*Corresponding author (email: xhgou@1zu.edu.cn) which limited drinking water for about 24.25 million people and 15.84 million head of livestock; 7.73 million hectares of farm land lacked adequate irrigation (China Daily, reported on March 31, 2010). Therefore, additional climatic-hydrographical studies are urgently needed in this area. Instrumental measurement is sparse and short-term in southwestern China, but climatic conditions can be extended back several centuries with high-resolution climatic proxies. Tree-ring records are widely used as climatic proxies, because they provide annual resolution, precise dating and adequate duplicate data and have been proven to be an efficient proxy for past climate reconstruction [1-5].

Some scholars have reconstructed past climate data using 
tree-ring records in the Hengduan Mountains. Most of the samples were collected from high elevation $(>3400 \mathrm{~m})$ [6-11], and with the rich precipitation in this area, most of these studies had reconstructed temperature variation. Only a few of them were related to variations in precipitation or the Palmer Drought Severity Index (PDSI) $[12,13]$ and their samples were usually collected from lower altitudes $(<3240$ $\mathrm{m}$ ). As mentioned, the complex terrain and the highly diverse regional environment strongly suggest additional climatichydrographical research is needed. We collected tree-ring samples from the middle Hengduan Mountains and studied the climate-growth response relationships. By comparing nearly 500 years of reconstructed rainfall history with other moisture sensitive tree-ring serials as well as the spatial correlation analysis, we successfully explored the spatial representativeness of the reconstruction and studied the dry/ pluvial variation patterns in this district for the last five centuries.

\section{Materials and methods}

\subsection{Study area}

The sampling site lies in the north-central part of the Hengduan Mountains, in Xiangcheng County of Ganzi Tibetan Autonomous Prefecture, at the southwestern rim of Sichuan Province (Figure 1); this is the transition zone between the Qinghai-Tibet Plateau and the Yunnan-Guizhou Plateau. Three rivers (Shuoqu, Dingqu, and Mayi rivers) cut this region into a complex area of high mountains and steep gorges while the highest peak reaches $5336 \mathrm{~m}$ a.s.l. Subtropical high-pressure controls the regional climate and precipitation is mainly derived by the Southwest Monsoon, East Asian Monsoon and Plateau Monsoon [14]. The nearest meteorology station, Daocheng Station $\left(29^{\circ} 03^{\prime} \mathrm{N}, 100^{\circ} 18^{\prime} \mathrm{E}\right.$, $3727.7 \mathrm{~m}, 1957-2006)$, is located approximately $36 \mathrm{~km}$ east of the sampling site. Average annual precipitation, $642.1 \mathrm{~mm}$, falls primarily in July and August which comprises $54.5 \%$ of annual rainfall. Mean annual temperature is $4.4^{\circ} \mathrm{C}$ with the highest temperature always occurring in June or July (Figure 2). The mountainous area vegetation is clearly divided into zones based on elevation with the elevation of forested zones occurring at about 2400-4000 m. The main conifers in this area are Abies Mill., Tsuga Carr. and Picea Mill.; shrubs belong to the genera of Cuculus L., Potentilla L., Caragana Fabr. and Spiraea L.; common alpine meadow species usually belong to the Poaceae, Cyperaceae, Asteraceae and Ranunculaceae [14].

\subsection{Samples and chronology}

Tree-ring cores were obtained from a steep shady slope $\left(29^{\circ} 09^{\prime} \mathrm{N}, 99^{\circ} 56^{\prime} \mathrm{E}, 3530 \mathrm{~m}\right.$ a.s.1.). The north facing slope has a gradient of $50-60^{\circ}$. Abies forrestii Coltm.-Rog. dominates the site; among these trees there are a few Picea

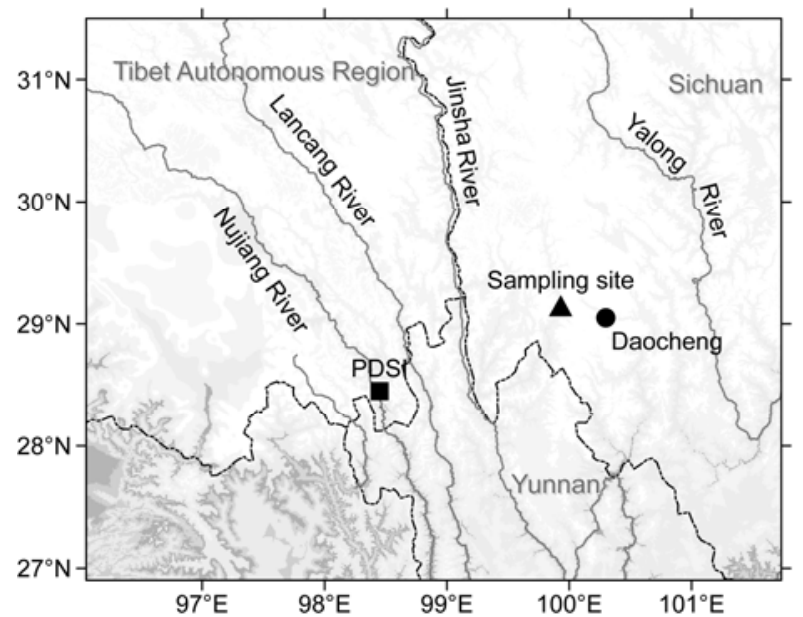

Figure 1 Sampling site, the nearest meteorology station and the PDSI grid point.

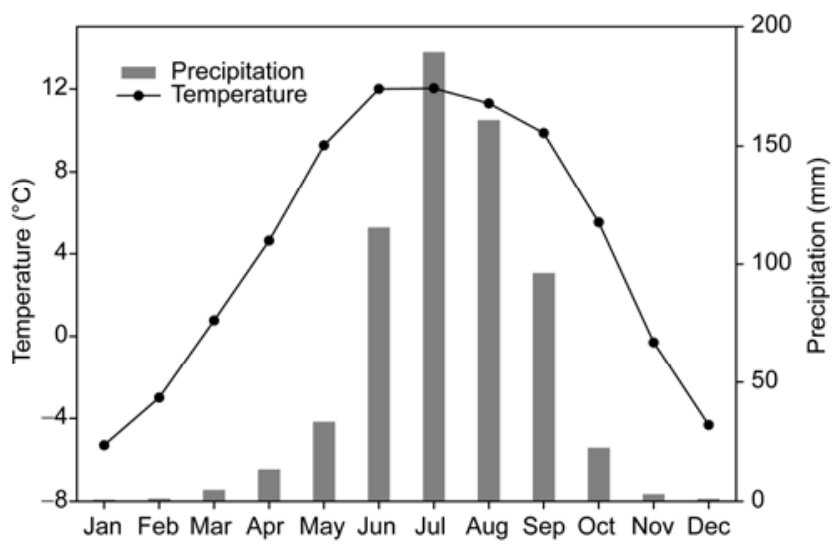

Figure 2 Average monthly temperature and precipitation of Daocheng Station (1957-2006).

likiangensis Pritzel var. balfouriana Rehd. et Wilis. Forest canopy density is $0.3-0.4$. Because of the steep gradient and the leeward slope, the foehn effect might cause the sampling site to become a rain shadow area. Soil cannot always retain enough moisture for plant growth; therefore, brush and herbaceous plant cover is rare. The 56 cores from 28 healthy trees were extracted at breast height.

Cores were taken back to the laboratory and air-dried, fixed onto wood holders and sanded with sandpaper until a highly polished surface was achieved [15]. Then the preliminarily dated cores were measured using a Velmex measuring system with the precision of $0.001 \mathrm{~mm}$. The measured series were checked by the COFECHA program [16] for quality control. Finally, five cores were eliminated because their growth trends were not similar to others. The COFECHA results show these tree ring series have a high mean sensitivity (0.323), and they are highly correlated (the coefficient is 0.796 ) with each other. These results indicate tree growth was sensitive to the environmental change. The percentage of absent rings was $0.260 \%$. The first order 
autocorrelation coefficient is 0.730 , which indicates annual tree growth was affected by previous growth.

To eliminate the non-climatic signals caused by the growth trend and other factors influencing ring-width chronologies, while maintaining more low-frequency climatic signals, we chose detrending methods carefully. In the standardization process with the program ARSTAN [17], linear and negative exponential functions were used to fit the growth trend for most ring-width series. For some series these methods were not suitable, so the Friedman Super-Smoothing method (parameter is 7) was employed to standardize the data. The 51 cores were ultimately used to build the chronology and 14 of them were detrended with the Friedman SuperSmoothing method. With ARSTAN, the detrended series were processed to produce the chronologies using the biweight robust mean. The ARSTAN chronology, which retained low-frequency variation and was strongly correlated with climate factors, was used for further analysis. We calculated the Expressed Population Signal (EPS) [18] and the correlation coefficients between serials (RBAR) using a moving 50 year-long window with an overlap of 25 years. The running EPS and RBAR (Figure 5(b)) values are both at a high level (mean RBAR=0.64, EPS $>0.96$ ), indicating the chronology is reliable during the entire time interval (15092006). The confidence of the chronologies was evaluated by the subsample signal strength (SSS $>0.85)$, and we obtained one reliable chronology spanning 1549-2006.

\subsection{Meteorological data}

Climatic data from Daocheng, the nearest meteorology station to the sampling site, was used for the analysis. A PDSI [19] grid $\left(28^{\circ} 45^{\prime} \mathrm{N}, 98^{\circ} 45^{\prime} \mathrm{E}, 1957-2006\right)$ was also chosen for growth-climate response analysis (Figure 1). Meteorological data for May 1968 was not available. Instead, we filled the missing data with the regression value of the adjacent meteorology stations, i.e. Muli, Jiulong, and Zhongdian, and the instrumental climate data passed the homogeneity test [20]. To study the spatial correlations, we applied monthly precipitation data from the Climate Research Unit (CRU TS 3.0, $\left.0.5^{\circ} \times 0.5^{\circ}, 1957-2006\right)$ [21]. The multi-taper method [22] was employed to analyze potential cycles of the regional rainfall in the past 500 years.

\section{Results and discussion}

\subsection{Relationships between tree growth and climatic factors}

We calculated the correlations between the chronology and climate data from the previous June to current September. Significant correlations were found between precipitation and tree-ring data in May and June of the current year $(P<0.01$; Figure 3$)$. Meanwhile, significant correlations between tree-ring data and temperature were found in January,

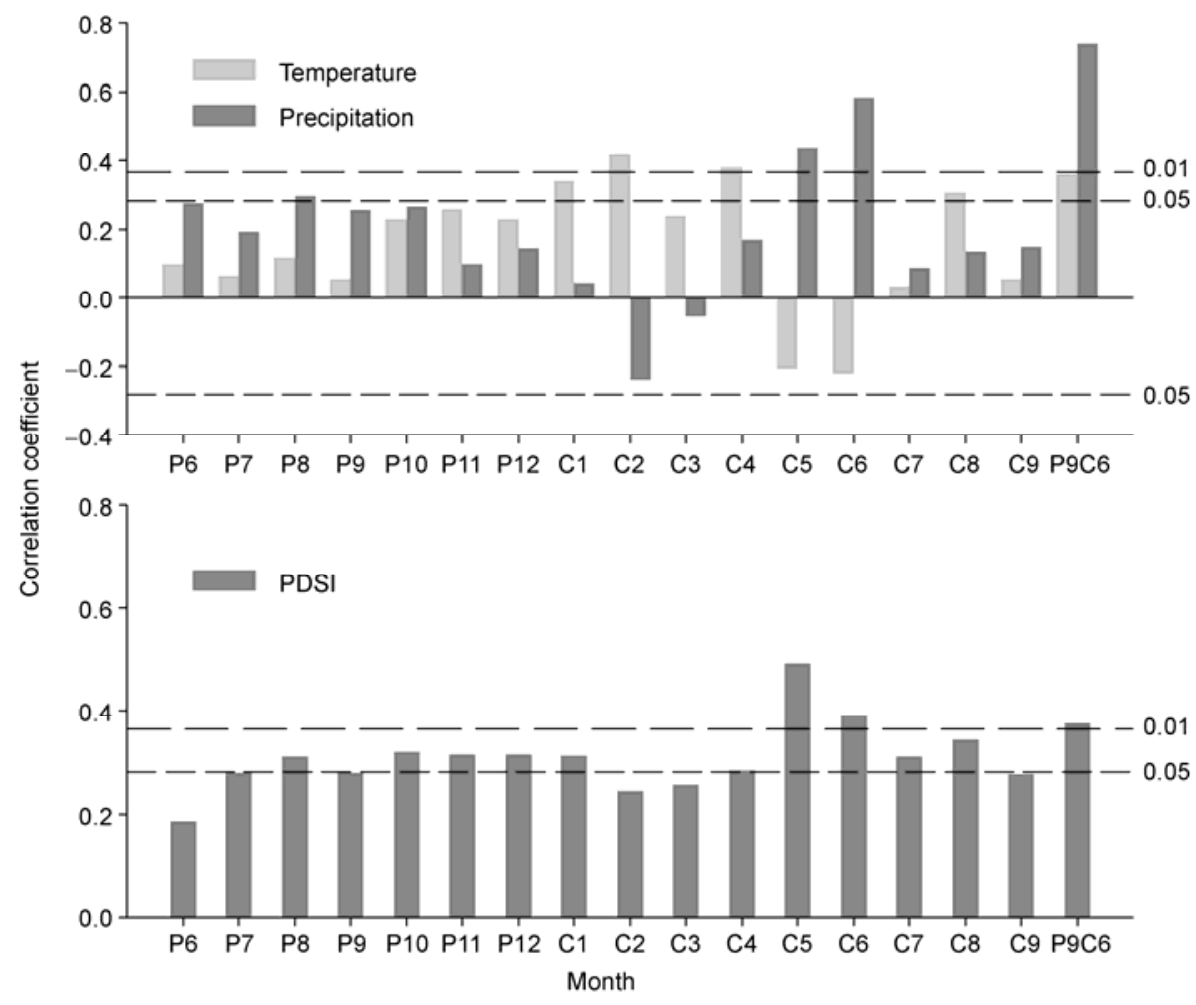

Figure 3 Correlation coefficients between tree-ring chronology and the climatic records for 1958-2006. P6 and C6 represent the previous June and the current June, respectively. 
February, April and August $(P<0.05)$. Seasonally averaged climatic variables were also used for correlation analysis, and the highest correlation coefficient $(0.738)$ was found with precipitation from the previous September to the current June (P9C6); the correlation coefficient with the previous July to the current June precipitation was also high (0.649). Meanwhile, the correlations between the PDSI and chronology were significant $(P<0.05)$ for most months, even reaching the $99 \%$ confidence level for the current May, June and the P9C6. So, we could conclude moisture limits the tree's annual growth in this region. However, rainfall in July and August accounted for $54.5 \%$ of annual precipitation; the high rainfall amounts could ease the drought limitation for the trees, so there was a weaker relationship between July and August rainfall and tree growth. At high elevations $(>3530 \mathrm{~m})$, precipitation in the previous November to current March may remain through the winter as snow and ice. Snow and ice would not increase soil moisture until the next warm period arrives. So, a clear relationship was not seen between tree growth and precipitation from November to March, but winter temperature in the former year was positively correlated with the tree-ring chronology. Such phenomena also existed in many other tree-ring studies $[10,23]$. In summary, ignoring July and August and selecting the previous September to the current June precipitation for reconstruction is reasonable.

\subsection{Nearly 500 year's precipitation reconstruction}

We developed a transform function between the tree-ring width index and the precipitation of the previous September to the current June.

$$
P_{9-6}=200.29 X+101.60 .
$$

Here, $P_{9-6}$ represents the reconstructed precipitation from September of the former year to June of the current year; $X$ represents the tree-ring width index.

The correlation coefficient is $0.738(N=49, P<0.01)$, and variance explanation $\left(R^{2}\right)$ is $54.4 \%\left(R_{\mathrm{adj}}^{2}=53.5 \%\right)$. The function $\mathrm{F}$ test value is 56.12. Segmented verification [24] results (Table 1) show that it has a high correlation coefficient both in the calibration and verification periods. It also passed the sign test $(P<0.01)$. Reduction of error $(\mathrm{RE})$ and coefficient of efficiency (CE) are two important statistical tests for paleoclimate reconstruction, and the RE and $\mathrm{CE}$ of our reconstruction are greater than zero, indicating the transfer function is reliable [25]. For 1958-2006, no matter the low-frequency or high-frequency variation, the reconstructed precipitation variability is very consistent with the actual instrumental value (Figure 4). It must be noted the reconstruction does not exactly capture the actual precipitation in some extreme years, e.g. in 1978-1979. We checked the daily precipitation data of June and September in 19771979 and the result show much more precipitation fell in September in 1977 and 1978 (129.9 mm, $233.5 \mathrm{~mm}$ respectively) than that in other years (monthly average precipitation is $96.8 \mathrm{~mm}$ for September). High levels of precipitation also occurred in June of 1978 (152.7 mm) and 1979 (201.4 $\mathrm{mm}$ ), when comparing with the average monthly precipitation for June (115.6 mm). For June and September of 19771979, days with rainfall greater than $20 \mathrm{~mm}$ occurred much more frequently than in other years. Tree-ring records failed to accurately record rapid and intensive rainfall, especially for the steep slopes at our sampling site, and this is a common phenomenon in tree ring research [26,27].

Using the above transform function, we reconstructed the previous September to current June precipitation history since 1509 (Figure 5(a)). During the reliable interval (15492006), mean precipitation was $298.18 \mathrm{~mm}$; standard deviation $(\sigma)$ was $51.42 \mathrm{~mm}$. We used the precipitation values of greater than mean $+2 \sigma$ and less than mean $-2 \sigma$ to represent extremely pluvial and dry years, respectively. Then, 11 extremely dry years $(1653,1670,1736,1799,1870,1885$, $1890,1897,1960,1977$ and 1983) and 15 pluvial years (1563, 1579, 1581, 1583, 1658, 1702, 1719, 1731, 1732, $1787,1788,1846,1847,1850$ and 2002) were observed in the reconstruction. Extremely dry years occurred very frequently in the last half part of the 19th and 20th century, while extremely pluvial years occurred more frequently in the 16th and 18th century. Compared with the dry/pluvial events in the history (1555-2000) of Chengdu, Kangding, Xichang, Dali from the Yearly charts of Dryness/Wetness in China for the last 500-year period [28], many extreme years (dry years such as 1983, 1960, 1897, 1670, as well as the pluvial years $1846,1847,1731,1788$ ) from the reconstruction can be found in the historical records. The 11-year fast Fourier transformation was employed to highlight the lowfrequency variation of the reconstruction. Several significant dry/pluvial periods (lasted longer than 20 years): $1597-$ 1656, 1662-1697, 1742-1776, 1798-1825, 1861-1896, 1950-

Table 1 Statistics of calibration and verification test results

\begin{tabular}{|c|c|c|c|c|c|c|c|c|}
\hline \multicolumn{4}{|c|}{ Calibration period } & \multicolumn{5}{|c|}{ Verification period } \\
\hline Time span & $r$ & $R^{2}$ & $F$ & Time span & $r$ & RE & $\mathrm{CE}$ & ST \\
\hline $1958-1981$ & 0.678 & 0.459 & $18.69^{\mathrm{a})}$ & 1982-2006 & 0.860 & 0.385 & 0.385 & $22 / 3^{a)}$ \\
\hline 1982-2006 & 0.860 & 0.740 & $65.17^{a)}$ & 1958-1981 & 0.678 & 0.280 & 0.279 & $17 / 7^{\text {b) }}$ \\
\hline 1958-2006 & 0.738 & 0.544 & $56.12^{\mathrm{a})}$ & & & & & \\
\hline
\end{tabular}

ST: Signal test, RE: reduction of error, CE: coefficient of efficiency; a) and b) indicate the $99 \%$ and $95 \%$ confidence level, respectively. 


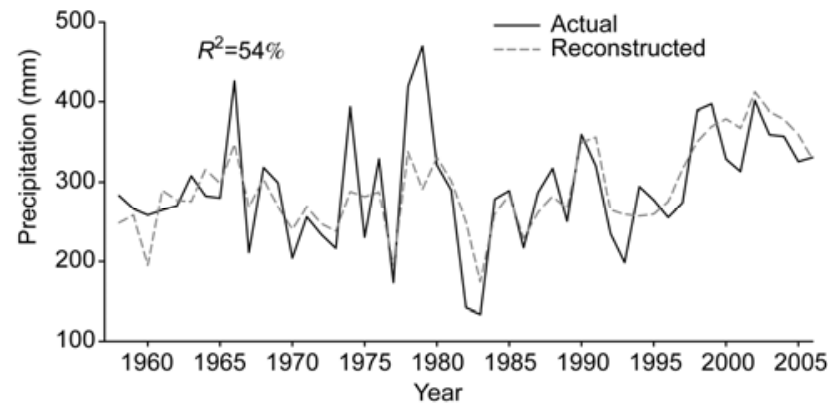

Figure 4 Comparison of the actual and reconstructed precipitation of previous September to current June (1958-2006).

1992 were dry periods. Also, 1568-1596, 1698-1741, 17771797, 1826-1860, 1927-1949 were pluvial periods. Dry periods lasted longer than pluvial periods. Precipitation in the 17 th century remained lower than the mean value for as long as 60 years. In the last 20 years, precipitation has shown an increasing trend.

\subsection{Comparison with other tree-ring based drought/ wetness reconstructions}

We compared our reconstruction with other tree-ring based drought/precipitation reconstructions in the Hengduan Mountains to validate our reconstruction. The three series used for comparison included a nearby PDSI grid $\left(28.75^{\circ} \mathrm{N}\right.$, $98.75^{\circ} \mathrm{E}$, Figure 6(b)) from the Monsoon Asia Drought Atlas [29], a spring (March-May) PDSI reconstruction (Figure 6(a)) derived by Fan et al. [12] and a yearly (from previous May to current April) PDSI reconstruction (Figure 6(d)) from Fang et al. [13]. All serials were standardized and smoothed with 11-year Fast Fourier transformation. Com- parison between these serials reveals that the drought/moisture variation is coherent in the low-frequency in the study area, especially for the two spatially nearest reconstruction sites (this study and Cook et al.'s work [29]). These four serials contain the same dry periods: 1760s-1770s, 1860s-1870s, 1970s-1980s; coherent pluvial periods occurred in the 1550s, 1720s-1730s, 1780s-1790s and all reconstructions in this area show a trend toward wetness since the 1990s. Also, Fan et al.'s work [12] confirms our reconstruction of the drought period of 1800-1820. Of course, there were unconformities in these four serials during some periods, which might be caused by the possible differences in microhabitat at the sampling site, and different seasonal periods reconstructed.

Spatial precipitation data from the Climate Research Unit (CRU TS $3.0,0.5^{\circ} \times 0.5^{\circ}, 1957-2006$ ) was used to correlate with the actual and the reconstructed P9C6 precipitation. We can see the spatial correlation calculated with instrumental data (Figure 7(a)) and the CRU precipitation data resembles that computed with the reconstruction serial data (Figure 7(b)). Those highly correlated areas (correlation coefficient greater than 0.5 ) all seem to center around the Hengduan Mountains, which is an explanation of our reconstruction is consistent with others. The spatial correlation analysis and comparisons with other tree-ring based drought/ wetness reconstructions all tell us our precipitation reconstruction represents the precipitation variation of the total Hengduan Mountains very well.

\subsection{Spectral analysis}

The multi-taper method was used to analyze the spectrum of the reconstruction; it contains several significant $(P<0.01)$

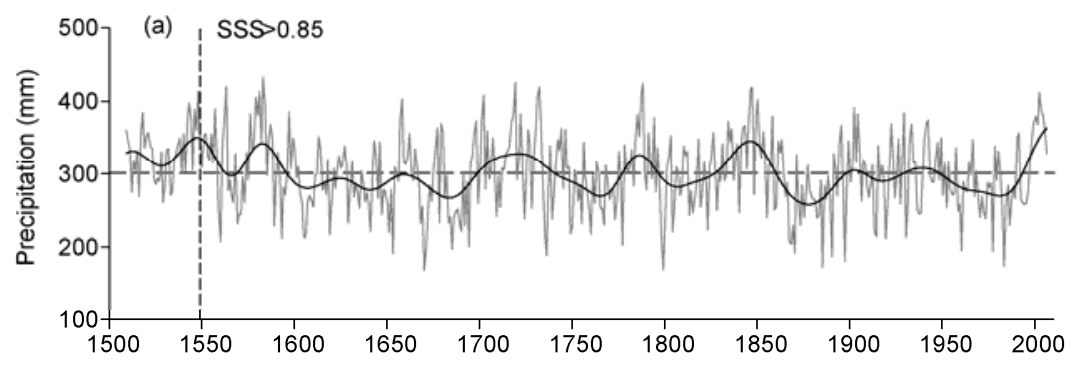

(b)
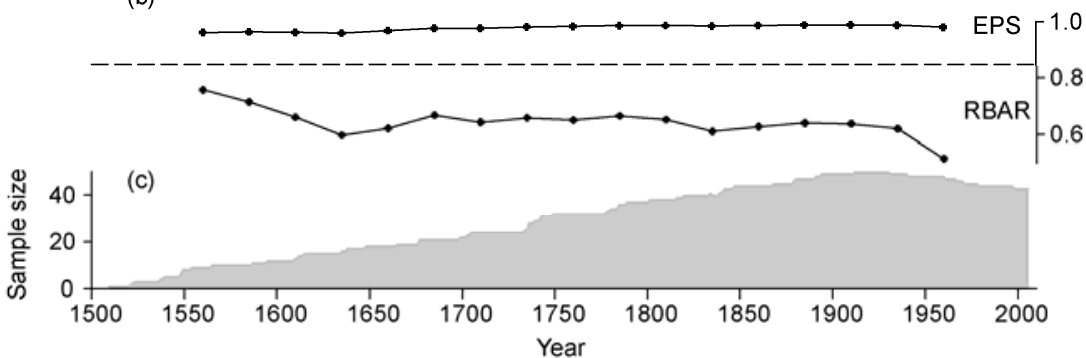

Figure 5 (a) Reconstructed previous September to current June precipitation from 1509 to 2006; the thick curve is the 11-year Fast Fourier transformation, which stands for low-frequency variation; the dashed line is the start year of the reliable time span (subsample signal strength $>0.85$ ); (b) running EPS and RBAR (a moving 50 year-long window with an overlap of 25 years); (c) sample size (cores). 


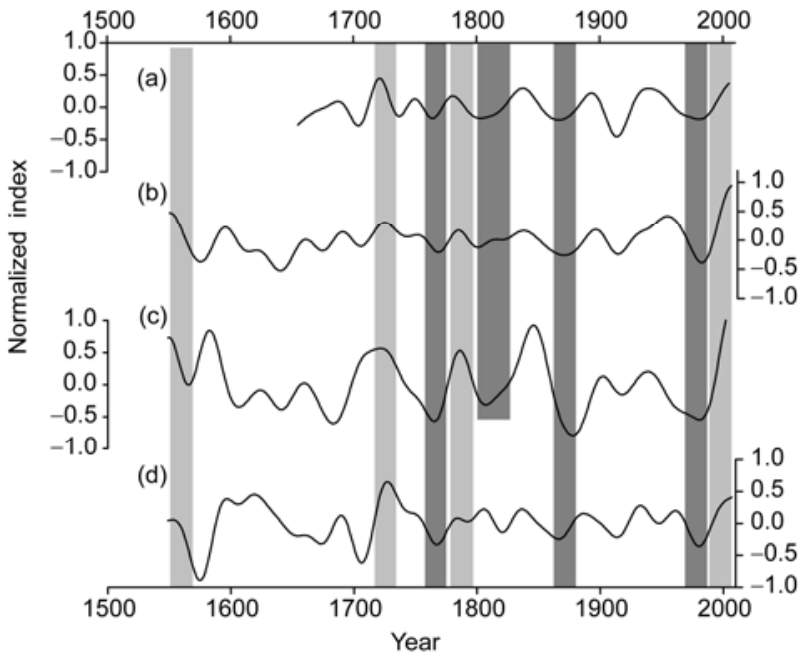

Figure 6 Comparison between the reconstructed precipitation and other tree-ring based dryness/wetness change records. (a)-(d) are standardized and their 11-year Fast Fourier transformation serials. (a) Reconstructed March to May's PDSI of the Hengduan Mountains by Fan et al. [12]; (b) reconstructed PDSI gird point records near the sampling site by Cook et al. [29]; (c) authors' reconstructed rainfall (previous September to current June) in this text; (d) reconstructed previous May to current April PDSI by Fang et al. [13]; dark-gray shading represents dry periods; gray shading represents pluvial periods.

multi-decadal and interannual cycles (Figure 8). There are cycles of 79-85 years and quasi-60 year in low-frequency, and 3-5 years cycles in high-frequency. The significant spectral peaks of 3-5 years fall within the range of variability of the El-Niño Southern Oscillation (ENSO), and reveal a possible teleconnection between the local precipitation variability and the ENSO activity [30,31]; the 60-year cycle might suggest the influence of the Pacific Decadal Oscillation (PDO) and the North Atlantic Oscillation (NAO) [13,32]. Correlation analysis results between the reconstruction and the global sea surface temperature (SST, 1957-2006, not shown in the figures) indicated precipitation in the study area had a remarkable teleconnection $(P<0.01)$ with the sea surface temperature of the Indian Ocean, west and north equatorial Pacific, north Atlantic, middle of the south equatorial Pacific and the Arctic ocean. They provide further evidence of the connection between the local precipitation and the atmospheric moisture-heat circulation, and these connections may be related to water-vapor transfer from the Indian Ocean by the South Asia monsoon, through the upper air of southwestern China. But this hypothesis needs to be verified by additional atmospheric physical and simulation evidence. Instrumental records and the reconstructed precipitation both show a trend of increasing moisture since 1983, and this trend is likely to be related to the strong stage of the South Asia monsoon [33]; the 79-85 cycle maybe related with solar activity $[34,35]$. Also, many other reconstructions nearby based on tree rings revealed similar cycles $[11,13]$.

\section{Conclusions}

Previous September to current June precipitation history from 1549 to 2006 has been derived from an Abies forrestii Coltm.-Rog. chronology in the Hengduan Mountains. The transform function was verified as stable and reliable. In the reconstructed precipitation history, there are 11 extreme dry and 15 extreme pluvial years. Some of the extremely dry years $(1983,1960,1897,1670)$ and wet years $(1846,1847$, 1731,1788 ) conform to the rainless (grade $\geqslant 4$ ) and rainy (grade $\leqslant 2$ ) years from the Yearly Charts of Dryness/ Wetness in China for the last 500-year. Six long drought periods are confirmed as: 1597-1656, 1662-1697, 1742-1776, 17981825, 1861-1896 and 1950-1992; five long pluvial periods are: $1568-1596,1698-1741,1777-1797,1826-1860$ and 1927-1949. According to the reconstruction, drought lasted longest in the 17 th century. In comparison with other treering based moisture reconstructions, we found they present

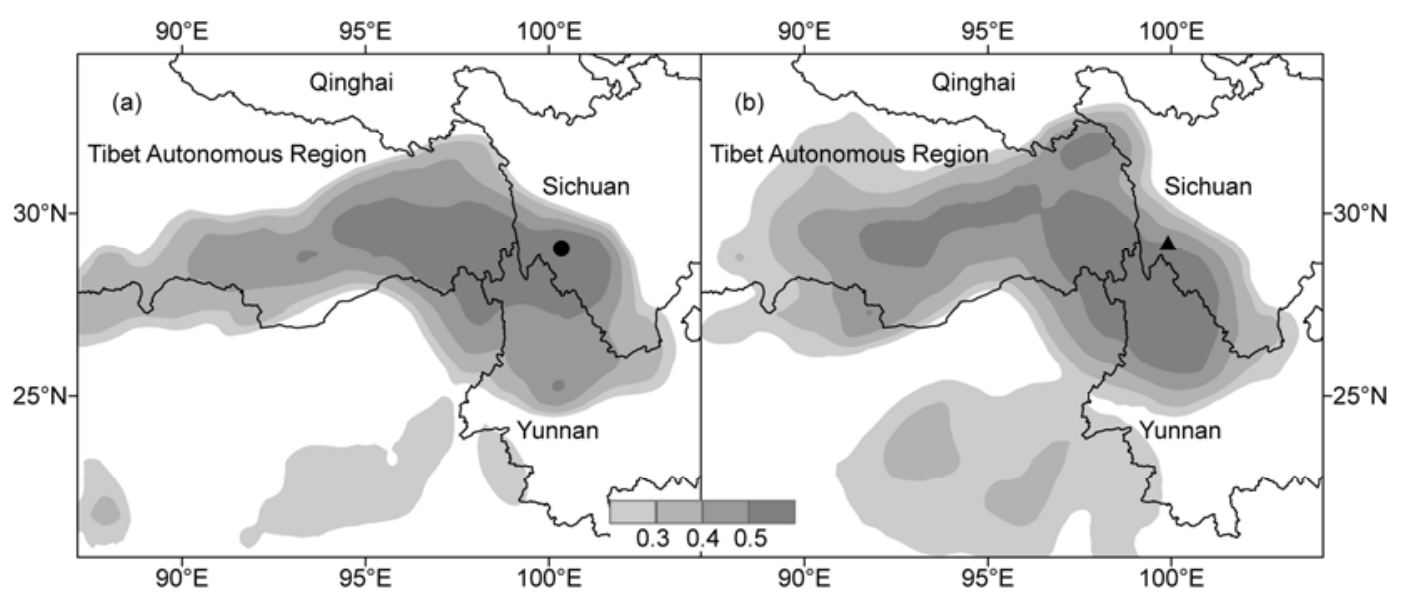

Figure 7 Spatial correlations from previous September to current June for instrumental precipitation (a), reconstructed precipitation (b) and CRU precipitation data (1958-2006). The dot represents the location of the Daocheng Meteorology Station and the triangle represents the sampling site. 


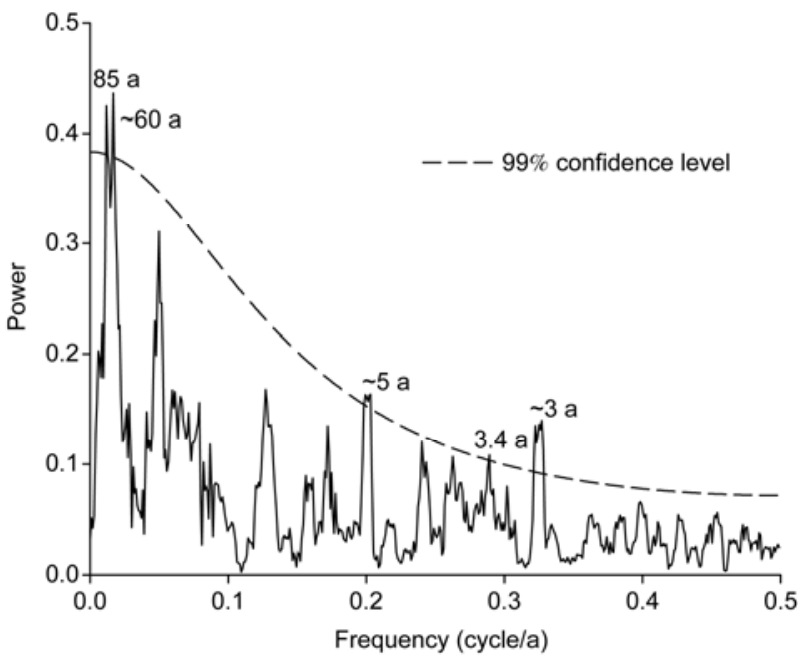

Figure 8 Spectrum analysis result of the reconstructed precipitation (1549-2006).

a similar trend and variation, and the region became wetter in the last 20 years. The tree-ring record in the study area is a reliable moisture proxy for a large region. Spatial correlation analysis also indicates the authors' precipitation reconstruction might be applicable to represent dry/wet variations for the entire southeastern part of the Qinghai-Tibet Plateau and the Hengduan Mountains. Spectral analysis shows the precipitation variation in this region has significant spectral peaks $(P<0.01)$, such as $3-5 a, 60$ a and $79-85 a$, which indicates local precipitation is probably related to the ENSO, PDO, NAO as well as solar activity. The impact of the combined effects of ocean and atmosphere on precipitation requires further study using atmospheric physics and simulation methods. Meanwhile, to uncover the mechanisms influencing regional precipitation, more high-resolution climatic proxies in a larger regional scale are needed for accurate spatial precipitation reconstruction and characteristic analysis.

The authors would like to thank Dr. Zexin Fan for data support and thank Prof. Ruhai Wang of Lamar University (USA) for improving the English. The authors are grateful for the advice and suggestions given by the peer reviewers and editors of the Chinese Science Bulletin. This work was supported by the National Natural Science Foundation of China (41171039 and 40890051), the Chinese NSFC Innovation Team Project (41021091), the One Hundred Talents Program of Chinese Academy of Sciences (290827B11) and the Program of Introducing Talents of Discipline to Universities from China's Ministry of Education (B06026).

1 Zhang Q B, Cheng G D, Yao T D, et al. A 2326-year tree-ring record of climate variability on the northeastern Qinghai-Tibetan Plateau. Geophys Res Lett, 2003, 30: 1739

2 Gou X H, Deng Y, Chen F H, et al. Tree ring based streamflow reconstruction for the Upper Yellow River over the past 1234 years. Chin Sci Bull, 2010, 55: 4179-4186

3 Liu Y, An Z S, Linderholm H W, et al. Annual temperatures during the last 2485 years in the mid-eastern tibetan plateau inferred from tree rings. Sci China SerD-Earth Sci, 2009, 52: 348-359
4 Shao X M, Xu Y, Yin Z Y, et al. Climatic implications of a 3585-year tree-ring width chronology from the northeastern Qinghai-Tibetan Plateau. Quat Sci Rev, 2010, 29: 2111-2122

5 Yuan Y J, Jin L Y, Shao X M, et al. Variations of the spring precipitation day numbers reconstructed from tree rings in the Urumqi River drainage, Tianshan Mts. over the last 370 years. Chin Sci Bull, 2003, 48: $1507-1510$

6 Fan Z X, Bräuning A, Yang B, et al. Tree ring density-based summer temperature reconstruction for the central Hengduan Mountains in southern China. Glob Planet Change, 2009, 65: 1-11

7 Liang E Y, Shao X M, Qin N S. Tree-ring based summer temperature reconstruction for the source region of the Yangtze River on the Tibetan Plateau. Glob Planet Change, 2008, 61: 313-320

8 Wang L L, Duan J P, Chen J, et al. Temperature reconstruction from tree-ring maximum density of Balfour spruce in eastern Tibet, China. Int J Climatol, 2010, 30: 972-979

9 Yang B, Kang X C, Liu J J, et al. Annual temperature history in southwest Tibet during the last 400 years recorded by tree rings. Int $\mathrm{J}$ Climatol, 2009, 30: 962-971

10 Shao X M, Fan J M. Past Climate on west Sichuan Plateau as reconstructed from ring-widths of Dragon spruce (in Chinese). Quat Sci, 1999, 19: 81-89

11 Li Z S, Zhang Q B, Ma K P. Tree-ring reconstruction of summer temperature for AD 1475-2003 in the central Hengduan Mountains, Northwestern Yunnan, China. Climatic Change, 2012, 110: 455-467

12 Fan Z X, Bräuning A, Cao K F. Tree-ring based drought reconstruction in the central Hengduan Mountains Region (China) since A.D. 1655. Int J Climatol, 2008, 28: 1879-1887

13 Fang K Y, Gou X H, Chen F H, et al. Reconstructed droughts for the southeastern Tibetan Plateau over the past 568 years and its linkages to the Pacific and Atlantic Ocean climate variability. Clim Dynam, 2010, 35: 577-585

14 Zhao J, Chen C K. Geography of China (in Chinese). Beijing: Higher Education Press, 1999

15 Stokes M A, Smiley T L. An Introduction to Tree-ring Dating. Chicago: University of Chicago Press, 1968

16 Holmes R L. Computer-assisted quality control in tree-ring dating and measurement. Tree-ring Bull, 1983, 43: 69-78

17 Cook E R. A time series analysis approach to tree ring standardization. Dissertation for the Doctoral Degree. Arizona: The University of Arizona, 1985

18 Wigley T, Briffa K R, Jones P D. On the Average Value of Correlated Time Series, with Applications in Dendroclimatology and Hydrometeorology. J Clim Appl Meteorol, 1984, 23: 201-213

19 Dai A G. Characteristics and trends in various forms of the Palmer Drought Severity Index during 1900-2008. J Geophys Res, 2011, 116: D12115

20 Holmes R L. Documentation for programs in the dendrochronology program library and the dendroecology program library. Laboratory of Tree-Ring Research, University of Arizona, 1999

21 Mitchell T D, Jones P D. An improved method of constructing a database of monthly climate observations and associated high-resolution grids. Int J Climatol, 2005, 25: 693-712

22 Mann M E, Lees J M. Robust estimation of background noise and signal detection in climatic time series. Climatic Change, 1996, 33: 409-445

23 Song H M, Liu Y, Ni W M, et al. Winter mean lowest temperature derived from tree-ring width in Jiuzhaigou Region, China Since 1750 A.D (in Chinese). Quat Sci, 2007, 27: 486-491

24 Meko D, Graybill D A. Tree-ring reconstruction of Upper Gila River discharge. Water Resour Bull, 1995, 31: 605-616

25 Cook E R, Meko D M, Stahle D W, et al. Drought reconstructions for the continental United States. J Climate, 1999, 12: 1145-1162

26 Liang E Y, Shao X M, Liu X H. Annual precipitation variation inferred from tree rings since AD 1770 for the western Qilian Mts., northern Tibetan Plateau. Tree-Ring Research, 2009, 65: 95-103

27 Yang B, Qin C, Bräuning A, et al. Rainfall history for the Hexi Corridor in the arid northwest China during the past 620 years derived from tree rings. Int J Climatol, 2011, 31: 1166-1176 
28 Chinese Academy of Meteorological Sciences. Yearly Charts of Dryness/Wetness in China for the Last 500-Year Period (in Chinese). Beijing: Map Press, 1981

29 Cook E R, Anchukaitis K J, Buckley B M, et al. Asian monsoon failure and megadrought during the last millennium. Science, 2010, 328: 486-489

30 Jiang X W, Li Y Q. Spatio-temporal variability of winter temperature and precipitation in Southwest China. J Geogr Sci, 2011, 21: 250-262

31 Gao Y, Wang H J. Pan-Asian monsoon and its definition, principal modes of precipitation, and variability features. Sci China Earth Sci, 2012, 55: 787-795
32 D'Arrigo R, Wilson R. On the Asian expression of the PDO. Int J Climatol, 2006, 26: 1607-1617

33 Yadav R, Bräuning A, Singh J. Tree ring inferred summer temperature variations over the last millennium in western Himalaya, India. Clim Dynam, 2011, 36: 1545-1554

34 Zhu J H, Wang S W. 80 yr oscillation of summer rainfall over North China and East Asian Summer Monsoon. Geophys Res Lett, 2002, 29: 1672

35 Wang S W, Zhao Z C, Chen Z H. Reconstruction of the summer rainfall regime for the last 500 years in China. Geojournal, 1981, 5: $117-122$

Open Access This article is distributed under the terms of the Creative Commons Attribution License which permits any use, distribution, and reproduction in any medium, provided the original author(s) and source are credited. 